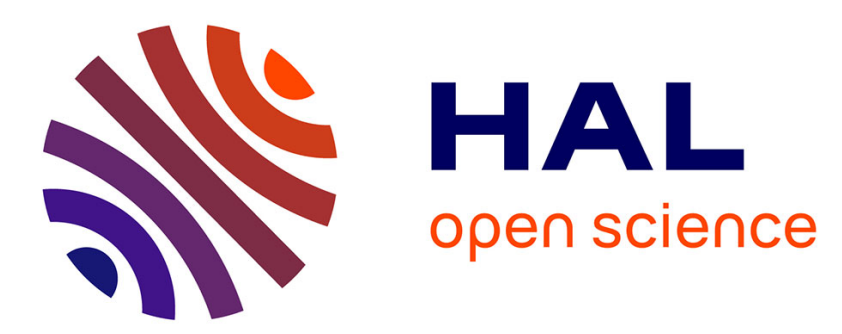

\title{
Prevalence of obstructive sleep apnoea in acute coronary syndrome: Routine screening in intensive coronary care units
}

\author{
S. Morra, François Bughin, K. Solecki, M. Aboubadra, B. Lattuca, Fares \\ Gouzi, J.-C. Macia, T.-T. Cung, S. Cade, F. Cransac, et al.
}

\section{To cite this version:}

S. Morra, François Bughin, K. Solecki, M. Aboubadra, B. Lattuca, et al.. Prevalence of obstructive sleep apnoea in acute coronary syndrome: Routine screening in intensive coronary care units. Annales de Cardiologie et d'Angéiologie, 2017, 66 (4), pp.223-229. 10.1016/j.ancard.2017.04.018 . hal-01759849

\section{HAL Id: hal-01759849 \\ https://hal.science/hal-01759849}

Submitted on 18 Dec 2019

HAL is a multi-disciplinary open access archive for the deposit and dissemination of scientific research documents, whether they are published or not. The documents may come from teaching and research institutions in France or abroad, or from public or private research centers.
L'archive ouverte pluridisciplinaire HAL, est destinée au dépôt et à la diffusion de documents scientifiques de niveau recherche, publiés ou non, émanant des établissements d'enseignement et de recherche français ou étrangers, des laboratoires publics ou privés. 


\title{
Prevalence of obstructive sleep apnoea in acute coronary syndrome: Routine screening in intensive coronary care units
}

\section{Fréquence de l'apnée du sommeil dans la cardiopathie ischémique en phase aiguë : dépistage} systématique chez les patients admis en soins intensifs cardiologiques pour syndrome coronaire aigu

S. Morra ${ }^{\text {a,b }}$, F. Bughin ${ }^{c}$, K. Solecki $^{\text {a }}$, M. Aboubadra ${ }^{\text {a }}$, B. Lattuca ${ }^{\text {a }}$, F. Gouzi ${ }^{\text {a }}$, J.-C. Macia ${ }^{\text {a }}$, T.-T. Cung ${ }^{\text {a }}$, S. Cade ${ }^{\text {a }}$, F. Cransac ${ }^{\mathrm{a}}$, J.-M. Davy ${ }^{\mathrm{a}}$, Y. Dauvilliers ${ }^{\mathrm{a}}$, D. Corrado ${ }^{\mathrm{b}}$, F. Roubille $^{\mathrm{a}, \mathrm{d}, *}$

${ }^{a}$ Cardiology Department, Arnaud-de-Villeneuve Hospital, Medical University of Montpellier, 371, avenue du Doyen-Gaston-Giraud, 34295 Montpellier cedex 05, France

${ }^{\mathrm{b}}$ Department of Cardiac, Thoracic, and Vascular Sciences, University of Padua Medical School, Via Giustiniani 2, 35121 Padova, Italy

${ }^{\mathrm{c}}$ Inserm U1046, CNRS UMR 9214, Physio, University of Montpellier, 34295 Montpellier cedex 5, France

d Inserm U1046, CNRS UMR 9214, PhyMedExp, University of Montpellier, 34295 Montpellier cedex 5, France

\begin{abstract}
Introduction. - Increased evidence has shown that, despite the maximum care afforded to patients admitted with acute coronary syndromes (ACS), a residual risk of mortality remains, in which obstructive sleep apnoea (OSA) appears to be a largely undiagnosed factor, particularly in the intensive cardiac care unit (ICCU). The purpose of this study is to determine whether the systematic screening for sleep-disordered breathing (SDB) is feasible and may be recommended. The aims of our study are to determine: (1) The estimated prevalence of OSA in patients admitted to the ICCU for ACS determined by a validated, user-friendly portable screening device; (2) The feasibility of the screening in this context; (3) To assess any negative impact of OSA on the severity of ACS.

Patients and methods. - This is an observational study of 101 patients admitted to the ICCU for ACS showing no clinical evidence of heart failure (HF). In the 24-72 hours following admission, they underwent an overnight sleep study using a 3-channel portable screening device with automatic analysis.

Results. - Sixty-two out of the 101 patients proved positive to the screening test, and its feasibility was acceptable. OSA patients tended to have greater peak levels of hs-cTnT $(3685 \pm 3576 \mathrm{ng} / \mathrm{L}$ versus $2830 \pm 3333 \mathrm{ng} / \mathrm{L}, P=0.08)$ than the non-OSA group. Compared with the non-OSA group, OSA patients presented more severe ACS, with a greater average GRACE score at admission of 112.2 \pm 26.3 (versus $98.4 \pm 19.2, P<0.001$ ). In the OSA group, we found a statistically significant inverse correlation between the apnoea-hypopnea index (AHI) and the left ventricular ejection fraction (LVEF) in the linear regression analysis $(r=-0.26 ; P=0.037)$.

Conclusions. - A systematic screening of patients in the ICCU is acceptable. OSA is frequently found in the acute phase of ischaemic heart disease and its presence is associated with more severe ACS and a poorer left ventricle systolic function.
\end{abstract}

Keywords: Acute myocardial infarction; Sleep-disordered breathing; Portable monitoring screening device; Heart failure

\section{Résumé}

Introduction. - Actuellement, un grand nombre d'études tend à montrer que, malgré les efforts maximaux destinés aux patients hospitalisés pour un syndrome coronarien aigu, un certain risque résiduel de mortalité persiste, dans lequel les apnées obstructives du sommeil semblent jouer un

\footnotetext{
* Corresponding author at: Cardiology Department, UFR de Médecine, Hôpital Arnaud-de-Villeneuve, Université Montpellier 1, CHU de Montpellier, 371 , avenue du Doyen-Gaston-Giraud, 34295 Montpellier cedex 05, France.

E-mail addresses: sofiamorra89@gmail.com (S. Morra), francois.roubille@gmail.com (F. Roubille).
} 
rôle non négligeable et pourtant sous-estimé, surtout aux soins intensifs. Les objectifs de notre étude sont les suivants : (1) Déterminer la prévalence estimée de l'apnée obstructive du sommeil chez les patients admis aux soins intensifs cardiologiques pour syndrome coronarien aigu à l'aide d'un appareil de dépistage validé, simple et intuitif dans l'interprétation des résultats ; (2) Vérifier la faisabilité du screening dans ce contexte ; (3) Identifier tout retentissement négatif des apnées obstructives du sommeil sur la sévérité du syndrome coronarien aigu.

Patients et méthodes. - Il s'agit d'une étude observationnelle comprenant 101 patients admis aux soins intensifs cardiologiques pour syndrome coronarien aigu, sans signes cliniques d'insuffisance cardiaque. Dans les 24-72 heures suivant leur admission, les patients ont bénéficié d'un enregistrement nocturne du sommeil à l'aide d'un appareil de dépistage à trois paramètres avec analyse automatique.

Résultats. - Sur 101 patients au total, le test de dépistage était positif pour 62 d'entre eux et sa faisabilité dans le service de soins intensifs a été satisfaisante. Le taux plasmatique de hs-cTnT a une tendance à être plus élevé chez les patients atteints du syndrome d'apnée du sommeil par rapport au groupe non OSA ( $3685 \pm 3576 \mathrm{ng} / \mathrm{L}$ versus $2830 \pm 3333 \mathrm{ng} / \mathrm{L}, p=0,08)$. Par rapport au groupe non OSA, les patients qui souffrent d'apnée présentent un syndrome coronarien aigu plus sévère, avec un score de GRACE moyen à l'admission de 112,2 \pm 26,3 (versus 98,4 \pm 19,2, $p<0,001)$. Dans le groupe OSA, nous avons mis en évidence une corrélation inverse entre l'index d'apnée-hypopnée et la fraction d'éjection du ventricule gauche à l'analyse de régression linéaire ( $r=-0,26 ; p=0,037)$.

Conclusion. - Un dépistage systématique des apnées du sommeil chez les patients admis aux soins intensifs cardiologiques pour syndrome coronarien aigu est faisable. L'apnée obstructive du sommeil est fréquemment retrouvée dans la phase aiguë de la cardiopathie ischémique et sa présence est associée au syndrome coronarien aigu plus sévère avec une dysfonction systolique gauche significativement plus importante.

Mots clés : Infarctus du myocarde ; Trouble respiratoire du sommeil ; Appareil de dépistage portable ; Insuffisance cardiaque

\section{Abbreviations}

ACS acute coronary syndrome

AHI Apnea-Hypopnea Index

AASM American Academy of Sleep Medicine

BMI body mass index

CABG coronary artery bypass graft surgery

CAD coronary artery disease

CSA central sleep apnea

CPAP continuous positive air pressure

CVD cardiovascular disease

ESS Epworth Sleepiness Scale

ICCU intensive cardiology care unit

IH intermittent hypoxaemia

LVEF left ventricle ejection fraction

LV left ventricle

MI myocardial infarction

NSTEMI non ST-segment elevation myocardial infarction

OSA obstructive sleep apnoea

PCI percutaneous coronary intervention

PM portable monitor

PSG polysomnography

ROS reactive oxygen species

SAS sleep apnoea syndrome

SDB sleep-disordered breathing

STEMI ST-segment elevation myocardial infarction

UA unstable angina

\section{Introduction}

In spite of the maximum care currently given to patients admitted with acute coronary syndrome (ACS), a residual risk remains with several clinical outcomes [1]. One of the underestimated pathophysiological factors could be obstructive sleep apnoea (OSA).

OSA is characterised by recurrent nocturnal respiratory interruptions, resulting from the total or partial collapse of the upper respiratory ways. The consequent breathing difficulties act against them and lead to sleep fragmentation, metabolic and biological disorders, thus impacting on the neuropsychological and cardiovascular systems.

Firstly, OSA is a frequent respiratory disorder with detrimental health effects. Its current high prevalence will supposedly increase in future years because of the obesity epidemic, the aging of the general population and the improvement in cardiovascular treatments. For instance, among people aged 30 to 60 years, the prevalence of asymptomatic and underdiagnosed sleep disorder breathing (SDB) is $24 \%$ among men and $9 \%$ among women [2].

Secondly, OSA is considered as a potential cardiovascular risk factor [3]. Even though no patent causal relationship between OSA and cardiovascular disease (CVD) has been clearly established until now, its pathophysiological mechanisms could make sense in supporting such a relationship. Intermittent hypoxaemia (IH), due to cycled upper airway collapse, is responsible for abnormal sympathetic activation [4], endothelial dysfunction [5], oxidative stress [6] and inflammation [7] all of which could pave the way for cardiovascular outcomes, especially hypertension [8], atherosclerosis [9], cardiac arrhythmias [10], heart failure [11] and coronary artery disease [12].

OSA is, likewise, positively correlated with an increased morbidity and mortality in the cardiovascular population $[13,14]$ and seems to be an independent predictive factor in cardiovascular mortality after ACS [15].

However, the guidelines for the management of ACS do not provide any recommendation for systematic screening for OSA in the acute phase of ischaemic heart disease [16]. 
The aims of our study are, firstly, to assess the estimated prevalence of OSA in patients admitted to the ICCU with ACS by a validated and user-friendly portable screening device; secondly, to determine the feasibility of this approach in this context and thirdly, to assess any negative impact of OSA on the severity of both the ACS, evaluated by the GRACE score at the admission, and the consequences of the myocardial infarction, expressed by the troponin-based infarct size and the left ventricular dysfunction.

\section{Methods}

\subsection{Patients}

We prospectively recruited 138 patients admitted to the ICCU with ACS but without clinical evidence of heart failure, from January to August 2015, in a tertiary care center. Inclusion criteria for participation in the study was the established diagnosis of ACS with an atherosclerotic etiology confirmed by coronary angiogram. Exclusion criteria included left ventricular ejection fraction $(\mathrm{LVEF})<40 \%$, the use of continuous positive air pressure (CPAP) therapy and a non-atherosclerotic etiology of ACS. The presence of ACS was assessed by three main diagnostic tools: clinical history, ECG modifications and cardiac biomarker elevation. The ACS severity was evaluated using the following scores: the TIMI score for NSTEMI/UA, the TIMI score for STEMI and the GRACE score for all types of ACS.

After giving informed consent, all participants underwent an overnight sleep study using a 3-channel (nasal airflow, pulse and oxygen saturation) portable device (ApneaLink ${ }^{\mathrm{TM}}$ device, ResMed Corporation, Poway, Calif) within 24-72 hours following their admission to the ICCU. Estimated presence of OSA was considered where the apnoea-hypopnoea index (AHI) value was of at least 5 per hours, without taking into consideration symptoms. The ApneaLink AHI used for analysis was automatically analysed by the ApneaLink system.

The AHI was calculated as the average number of apnoeas and hypopnoeas per hour of sleep, in keeping with the recent update of the 2007 American Academy of Sleep Medicine (AASM) task force [17].

\subsection{Device description}

The ApneaLink ${ }^{\mathrm{TM}}$ device (ResMed Corporation, Poway, Calif) is a sleep monitoring device including nasal airflow, pulse and oxygen saturation. It is used as inexpensive screening tests for patients with type 2 diabetes mellitus [18] and in morbidly obese patients [19]. However, there are no studies providing information on the validity of this screening tool in ACS population in the ICCU context.

Limited-channel device analysing nasal airflow [20], or nasal pressure [21] as a surrogate of airflow, seems to provide accurate estimates of SDB indices with a high sensitivity and specificity. Such devices are promising as possible screening tools for OSA, since they are easy-to-use, inexpensive and well tolerated by the patient.

\subsection{Statistical analysis}

Data are presented as means \pm SD when normally distributed and median and interquartile ranges otherwise. The normal-

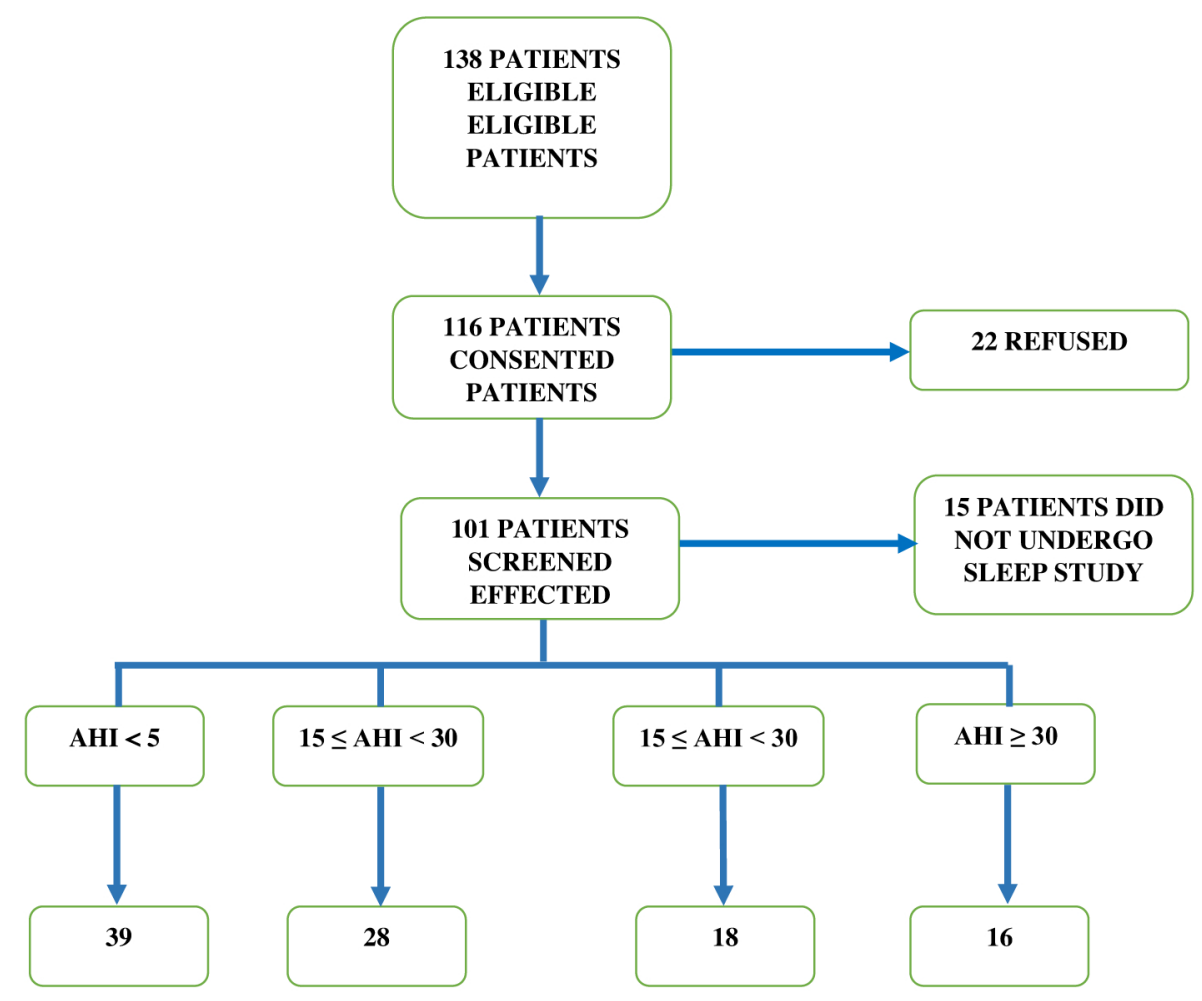

Fig. 1. Flow chart of patients through the study. AHI: apnoea-hypopnoea index. 
ity of the distribution was estimated by the D'Agostino \& Pearson omnibus normality test. The baseline sample characteristics were compared in the two groups. The Wilcoxon rank test was used to compare values of continuous variables and the Fisher's exact test was used for categorical variables. For GRACE score evaluation difference, the Student $t$-test was performed. Spearman rank correlation tests were used for the study of potential correlations. Differences were considered statistically significant at the 2 -sided $P<0.05$ level. All the statistical analyses were performed with the software GraphPad Prism (SAS Institute).

\section{Results}

As shown on Fig. 1, 138 consecutive patients admitted to our institution for ACS fulfilled the inclusion criteria; of these, 116 gave oral and written informed consent and 22 denied their participation. Fifteen consenting candidates withdrew from the overnight sleep study because of last minute refusal, device failure or technical problems; 101 successfully completed the examination. OSA was detected in 62 patients $(61.4 \%)$ : mild
OSA $(5 \leq \mathrm{AHI}<15)$ was found in 28 cases, with a prevalence of $27.7 \%$; moderate OSA $(15 \leq \mathrm{AHI}<30)$ was found in 18 cases $(17.8 \%)$; severe OSA (AHI $\geq 30$ ) was found in 16 cases $(15.8 \%)$. Moderate-to-severe OSA was found in $33.6 \%$ of cases, which equates to more than one third of patients.

Table 1 summarizes the clinical and demographic characteristics of patients.

With the exception of age $(61.3 \pm 12.2$ years in OSA group versus $54.5 \pm 10.2$ years in non-OSA group, $P<0.001)$ and BMI $\left(27.7 \pm 4.7 \mathrm{~kg} / \mathrm{m}^{2}\right.$ in OSA group versus $25.5 \pm 4.1 \mathrm{~kg} / \mathrm{m}^{2}$ in non-OSA group, $P<0.005$ ), we found no statistically significant differences in the distribution of the variables pertaining to gender, cardiovascular risk factors (smoking, hypertension, dyslipidemia, diabetes), comorbidities (previous myocardial infarction, atrial fibrillation, stroke), LVEF, number of coronary artery lesions, type of ACS (STEMI/NSTEMI/UA) and relative treatments (PCI, CABG, medical treatment).

In the unadjusted analysis, the plasma peak of hs-cTnT tended to be higher in OSA patients, with a mean level of $3685 \pm 3576$ (ng/L) in OSA group and $2830 \pm 3333$ (ng/L) in non-OSA group $(P=0.08)$.

Table 1

Patients' demographic and clinical baseline characteristics.

\begin{tabular}{|c|c|c|c|c|}
\hline & $\begin{array}{l}\text { Overall } \\
(n=101)\end{array}$ & Non-OSA group $(n=39)$ & OSA group $(n=62)$ & $P$-value \\
\hline Age & $58.7 \pm 11.9$ & $54.5 \pm 10.2$ & $61.3 \pm 12.2$ & $<0.001$ \\
\hline \multicolumn{5}{|l|}{ Sex } \\
\hline Men & $74(73.3 \%)$ & $27(69.2 \%)$ & $47(75.8 \%)$ & NS \\
\hline Women & $27(26.7 \%)$ & $12(30.8 \%)$ & $15(24.2 \%)$ & NS \\
\hline BMI & $26.8 \pm 4.6$ & $25.5 \pm 4.1$ & $27.7 \pm 4.7$ & $<0.005$ \\
\hline \multicolumn{5}{|l|}{$\mathrm{CV}$ risks factors } \\
\hline Smoking & $55(54.5 \%)$ & $21(53.9 \%)$ & $34(54.8 \%)$ & NS \\
\hline Hypertension & $36(35.6 \%)$ & $12(30.8 \%)$ & $24(38.7 \%)$ & NS \\
\hline Diabetes mellitus & $11(10.9 \%)$ & $2(5.1 \%)$ & $9(14.5 \%)$ & NS \\
\hline Dyslipidemia & $31(30.7 \%)$ & $11(28.2 \%)$ & $20(32.3 \%)$ & NS \\
\hline \multicolumn{5}{|c|}{ Previous history of cardiovascular diseases } \\
\hline Myocardial infarction & $12(11.9 \%)$ & $6(15.4 \%)$ & $6(9.7 \%)$ & NS \\
\hline Stroke & $2(2.0 \%)$ & $0(0 \%)$ & $2(3.2 \%)$ & NS \\
\hline Atrial fibrillation & $3(3.0 \%)$ & $0(0 \%)$ & $3(4.8 \%)$ & NS \\
\hline \multicolumn{5}{|l|}{ Acute coronary syndrome } \\
\hline STEMI & $74(73.3 \%)$ & $28(69.2 \%)$ & $46(75.8 \%)$ & NS \\
\hline NSTEMI & $25(24.8 \%)$ & $11(28.2 \%)$ & $14(22.6 \%)$ & NS \\
\hline UA & $2(2.0 \%)$ & $1(2.6 \%)$ & $1(1.6 \%)$ & NS \\
\hline hs-cTnT (ng/L) & $3355 \pm 3492$ & $2830 \pm 3333$ & $3685 \pm 3576$ & 0.08 \\
\hline $\operatorname{LVEF}(\%)$ & $51.9 \pm 6.3$ & $52.7 \pm 6.4$ & $51.5 \pm 6.2$ & NS \\
\hline \multicolumn{5}{|c|}{ Score of severity of the ACS } \\
\hline GRACE & $106.9 \pm 24.8$ & $98.4 \pm 19.2$ & $112.2 \pm 26.3$ & $<0.001$ \\
\hline TIMI STEMI & $3.3 \pm 1.7$ & $2.9 \pm 1.4$ & $3.6 \pm 1.7$ & NS \\
\hline TIMI NSTEMI/UA & $2.6 \pm 1.4$ & $2.8 \pm 1.1$ & $2.3 \pm 1.5$ & NS \\
\hline \multicolumn{5}{|c|}{ Number of vessels with CAD } \\
\hline One & $45(44.6 \%)$ & $19(48.7 \%)$ & $26(41.9 \%)$ & NS \\
\hline Two & $32(31.7 \%)$ & $11(28.2 \%)$ & $21(33.9 \%)$ & NS \\
\hline Three & $24(23.8 \%)$ & $9(23.1 \%)$ & $15(24.2 \%)$ & NS \\
\hline \multicolumn{5}{|l|}{ Treatments } \\
\hline PCI & $89(88.1 \%)$ & $35(89.5 \%)$ & $54(87.1 \%)$ & NS \\
\hline CABG & $10(9.9 \%)$ & $4(10.3 \%)$ & $6(9.7 \%)$ & NS \\
\hline Medical & $2(2.0 \%)$ & $0(0 \%)$ & $2(3.2 \%)$ & NS \\
\hline
\end{tabular}

Dates are expressed as $n(\%)$, or mean \pm SD. ACS: acute coronary syndromes; BMI: body-mass index; CABG: coronary artery bypass surgery; CAD: coronary artery disease; CV: cardiovascular; GRACE: global registry of acute coronary events; LVEF: left ventricle ejection fraction; NSTEMI: non ST-segment elevation myocardial infarction; PCI: percutaneous coronary intervention; STEMI: ST-segment elevation myocardial infarction; TIMI: thrombolysis in myocardial infarction; UA: unstable angina; NS: non significantNS: non significant. 


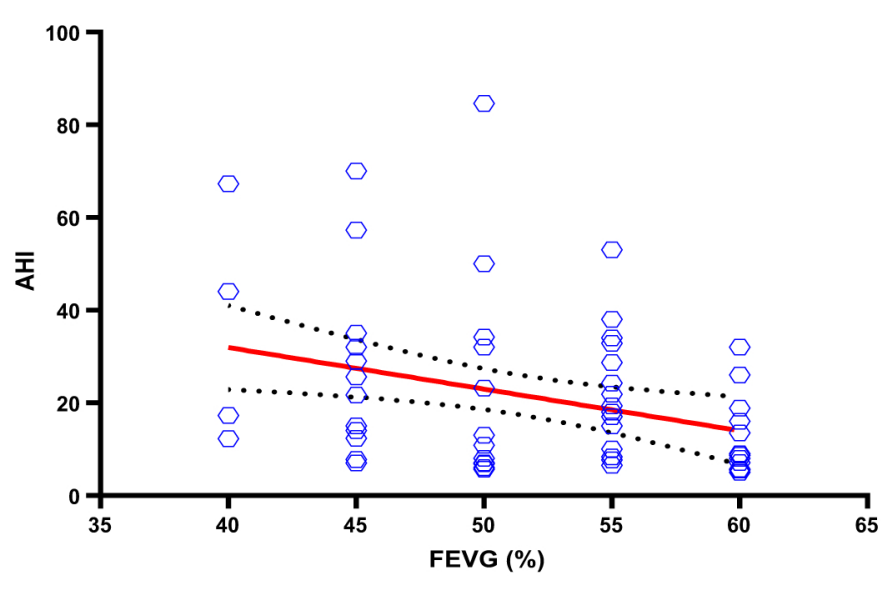

Fig. 2. Scatterplot of apnoea-hypopnoea index (AHI) and left ventricular ejection fraction (LVEF) in the obstructive sleep apnoea (OSA) group (AHI $\geq 5 / \mathrm{h}$ ): the higher AHI, the lower LVEF is. Linear regression analysis revealed a significant negative correlation between the two variables $(r=-0.26 ; P=0.037)$.

Interestingly, OSA patients presented more severe clinical manifestation of coronary syndrome, with a greater mean GRACE score at admission of $112.2 \pm 26.3$ (versus $98.4 \pm 19.2$, $P<0.001)$.

No difference in the severity of ACS between the two groups was found when the TIMI score was performed.

In OSA patients, we also found an inverse relationship between the obstructive respiratory events and the systolic function of LV: the higher the AHI, the lower LVEF. As shown in Spearman rank correlation, these two variables exhibited a statistical inverse linear correlation in the unadjusted model (Fig. 2).

\section{Discussion}

In this study, we have shown that the presence of OSA in the acute phase of ischaemic heart disease without clinical evidence of LV systolic dysfunction was very high, with an estimated prevalence of $61.4 \%$ when considering $\mathrm{AHI} \geq 5 / \mathrm{h}$; a systematic screening in the ICCU setting was acceptable. Moreover, we found that the presence of OSA was associated with more severe clinical and biological manifestations of ACS and with a more impaired LV systolic function.

The prevalence of obstructive sleep apnoea in coronary patients is higher than in general population [22]. In the acute phase of ischaemic heart disease, OSA was frequently found in several previous studies $[12,23,24]$, with a prevalence of moderate-to-severe class close to $69 \%$ [12].

As far as we are aware, there are other previous studies evaluating the interest in a very early screening of SDB in patients admitted for ACS in the ICCU setting [25,26], in both of which polysomnography (PSG) was performed.

We decided to use a 3-channel portable monitoring device screening tool; primarily because it is simple to use, an essential requirement when considering the context of an intensive care unit, and also because it is well tolerated by patient. Secondly, the simplicity of analysis, another important aspect, allows all physicians a correct interpretation of results. Thirdly, the rapidity of analysis avoids any prolongation of hospitalisation. In addition, increased evidence shows high sensitivity and specificity of this 3-channel monitoring device in comparison to full in-laboratory PSG, achieving the best result at an $\mathrm{AHI} \geq 15 / \mathrm{h}$ (sensitivity of $91 \%$ and a specificity of $94 \%$ ), with sensitivity greater than $80 \%$ for all AHI values; on the contrary, the specificity becomes lower as AHI values fall. However, these data are only applicable for diabetes patients [18].

Nevertheless, portable monitoring devices are not recommended by the task force of AASM, either for diagnosis of OSA in adult patients, mainly in those with significant medical comorbidities, or for general screening for asymptomatic population [27].

The significant negative relationship between the AHI and LVEF in apnoeic patients deserves to be investigated in both directions: the more severe the sleep apnoea, the more impaired the LVEF. Accordingly with previous studies [28,29], OSA is associated with a more impaired LV systolic function. A number of hypotheses, both haemodynamic and biological, could explain this relationship. First, the increased venous return due to the negative intrathoracic pressure is responsible for a reduction in LV pre-load (reduced LV end-diastolic volume secondary to a leftward shift of the interventricular septum); the increased afterload, secondary to the abnormal activation of the adrenergic system and the increased LV wall stress, contribute to a reduction of the cardiac output. Secondly, hypoxic-reoxygenation events, secondary to $\mathrm{IH}$, could increase myocardial damage by ROS production, resulting in a more profound and prolonged post-ischaemic stunning condition. Thirdly, vascular damage resulting from inflammation, oxidative stress and endothelial dysfunction could be responsible for coronary microvascular dysfunction, and thus, myocardial hypo perfusion, regardless of the results of revascularization. As microvascular perfusion is a necessary condition to allow myocardial contractility, hypo perfusion results in a reduction in contractility, in order to achieve the metabolic balance between $\mathrm{O}_{2}$ demand and $\mathrm{O}_{2}$ supply, and thus, an impairment of LV systolic function. All these hypotheses could explain why a more severe OSA is associated with a more impaired LV systolic function. On the other hand, LV systolic dysfunction could be just as responsible for body fluid retention, as great as more impaired LV function that could result in an increased collapsibility of upper respiratory way. This could explain why a more impaired LV function is associated with more severe obstructive respiratory events.

Finally, we demonstrated that the severity of ACS evaluated by the GRACE score at the admission is significantly higher in OSA group than non-OSA group. Further evaluations are needed to investigate the specific involvement of confounding factors such as age, gender, BMI and haemodynamic parameters.

This study needs to be analysed in the light of some important limiting factors.

First, as discussed above, ApneaLink is not a reliable method of assessing SDB [27]. In addition, the automatic analysis used for calculating the ApneaLink AHI is not recommended by the French guidelines [30] and this could underestimate the real values of the AHI and thus, the true prevalence and severity of OSA. ApneaLink technology is not even able to discriminate betweencentral sleep apnoea (CSA) and OSA [31], owing to 
a lack of respiratory events, limiting a better interpretation of results.

Secondly, the screening device does not consider the total sleep time and the sleep disruption frequently observed in ICCU patients [32] has not been further considered: a sleep questionnaire should have been included to allow a more suitable interpretation of results.

Thirdly, the cutoff $\mathrm{AHI} \geq 5 / \mathrm{h}$ chosen to discriminate between OSA and non-OSA patients is too low, as the most common threshold is $15 / \mathrm{h}[23,24]$, mainly because of the absence of daily symptoms in cardiovascular patients [33]. Moreover, above this threshold an increased mortality in heart failure patients is observed [34].

Finally, patients were not further investigated after their hospitalisation, limiting our conclusions on the real presence of SDB; its severity seems to change after the acute phase of myocardial infarction [23,24].

\section{Conclusions}

We found that more than half of patients admitted to the ICCU for ACS had evidence of SDB; this prevalence may be higher, the automatic analysis of the screening tool and sleep fragmentation underestimate the AHI values. The feasibility of such screening in the intensive care setting was acceptable and well tolerated by patients.

OSA seemed to be associated with more severe clinical manifestation of coronary syndromes, as shown by the greater mean GRACE score at admission and the more impaired LV systolic function. The inverse correlation between LVEF and the AHI suggests a potential role of myocardial ischaemia in the pathophysiology of obstructive sleep apnoea. Does a much more impaired LV systolic function increases the obstructive respiratory events, maybe secondary to greater body fluid retention?

However, further studies are necessary to answer several questions, such as the real interest of a very early screening of SDB in the acute phase of coronary syndromes, the natural course of SDB after the acute events and the usefulness of an appropriate treatment in decreasing the residual cardiovascular risk after a myocardial infarction.

\section{Disclosure of interest}

The authors declare that they have no competing interest.

\section{Acknowledgements and findings}

We would like to acknowledge École Santé for their technical support (ApneaLink ${ }^{\mathrm{TM}}$ device ResMed Corporation, Poway, Calif).

\section{References}

[1] Klempfner R, Elis A, Matezky S, Keren G, Roth A, Finkelstein A, et al. Temporal trends in management and outcome of diabetic and non-diabetic patients with acute coronary syndrome (ACS): residual risk of long-term mortality persists: Insights from the ACS Israeli Survey (ACSIS) 2000-2010. Int J Cardiol 2015;179:546-51.

[2] Young T, Palta M, Dempsey J, Skatrud J, Weber S, Badr S. The occurrence of sleep-disordered breathing among middle-aged adults. N Engl J Med 1993;328(17):1230-5.

[3] Parish JM, Somers VK. Obstructive sleep apnea and cardiovascular disease. Mayo Clin Proc 2004;79(8):1036-46.

[4] Somers VK, Dyken ME, Clary MP, Abboud FM. Sympathetic neural mechanisms in obstructive sleep apnea. J Clin Invest 1995;96(4):1897-904.

[5] Belaidi E, Joyeux-Faure M, Ribuot C, Launois SH, Levy P, Godin-Ribuot D. Major role for hypoxia inducible factor-1 and the endothelin system in promoting myocardial infarction and hypertension in an animal model of obstructive sleep apnea. J Am Coll Cardiol 2009;53(15):1309-17.

[6] Lavie L. Oxidative stress in obstructive sleep apnea and intermittent hypoxia - revisited - the bad ugly and good: implications to the heart and brain. Sleep Med Rev 2015;20:27-45.

[7] Shamsuzzaman AS, Winnicki M, Lanfranchi P, Wolk R, Kara T, Accurso V, et al. Elevated C-reactive protein in patients with obstructive sleep apnea. Circulation 2002;105(21):2462-4.

[8] Parati G, Lombardi C, Hedner J, Bonsignore MR, Grote L, Tkacova R, et al. Recommendations for the management of patients with obstructive sleep apnoea and hypertension. Eur Respir J 2013;41(3):523-38.

[9] Hoyos CM, Melehan KL, Liu PY, Grunstein RR, Phillips CL. Does obstructive sleep apnea cause endothelial dysfunction? A critical review of the literature. Sleep Med Rev 2015;20:15-26.

[10] Mehra R, Benjamin EJ, Shahar E, Gottlieb DJ, Nawabit R, Kirchner HL, et al. Association of nocturnal arrhythmias with sleep-disordered breathing: the Sleep Heart Health Study. Am J Respir Crit Care Med 2006;173(8):910-6.

[11] Bradley TD, Floras JS. Sleep apnea and heart failure: part I: obstructive sleep apnea. Circulation 2003;107(12):1671-8.

[12] Konecny T, Kuniyoshi FH, Orban M, Pressman GS, Kara T, Gami A, et al. Under-diagnosis of sleep apnea in patients after acute myocardial infarction. J Am Coll Cardiol 2010;56(9):742-3.

[13] Bradley TD, Floras JS. Obstructive sleep apnoea and its cardiovascular consequences. Lancet (London, England) 2009;373(9657):82-93.

[14] Won CH, Chun HJ, Chandra SM, Sarinas PS, Chitkara RK, Heidenreich PA. Severe obstructive sleep apnea increases mortality in patients with ischemic heart disease and myocardial injury. Sleep Breath 2013;17(1):85-91.

[15] Milleron O, Pilliere R, Foucher A, de Roquefeuil F, Aegerter P, Jondeau $\mathrm{G}$, et al. Benefits of obstructive sleep apnoea treatment in coronary artery disease: a long-term follow-up study. Eur Heart J 2004;25(9):728-34.

[16] Roffi M, Patrono C, Collet JP, Mueller C, Valgimigli M, Andreotti F, et al. 2015 ESC Guidelines for the management of acute coronary syndromes in patients presenting without persistent ST-segment elevation: Task Force for the Management of Acute Coronary Syndromes in Patients Presenting without Persistent ST-Segment Elevation of the European Society of Cardiology (ESC). Eur Heart J 2016;37(3):267-315.

[17] Berry RB, Budhiraja R, Gottlieb DJ, Gozal D, Iber C, Kapur VK, et al. Rules for scoring respiratory events in sleep: update of the 2007 AASM Manual for the Scoring of Sleep and Associated Events. Deliberations of the Sleep Apnea Definitions Task Force of the American Academy of Sleep Medicine. J Clin Sleep Med 2012;8(5):597-619.

[18] Erman MK, Stewart D, Einhorn D, Gordon N, Casal E. Validation of the ApneaLink for the screening of sleep apnea: a novel and simple singlechannel recording device. J Clin Sleep Med 2007;3(4):387-92.

[19] Fredheim JM, Roislien J, Hjelmesaeth J. Validation of a portable monitor for the diagnosis of obstructive sleep apnea in morbidly obese patients. J Clin Sleep Med 2014;10(7):751-7 [7a].

[20] Ayappa I, Norman RG, Seelall V, Rapoport DM. Validation of a selfapplied unattended monitor for sleep-disordered breathing. J Clin Sleep Med 2008;4(1):26-37.

[21] Grover SS, Pittman SD. Automated detection of sleep-disordered breathing using a nasal pressure monitoring device. Sleep Breath 2008;12(4):339-45.

[22] Lee CH, Khoo SM, Tai BC, Chong EY, Lau C, Than Y, et al. Obstructive sleep apnea in patients admitted for acute myocardial infarction. Prevalence, predictors, and effect on microvascular perfusion. Chest 2009;135(6): 1488-95. 
[23] Buchner S, Greimel T, Hetzenecker A, Luchner A, Hamer OW, Debl K, et al. Natural course of sleep-disordered breathing after acute myocardial infarction. Eur Respir J 2012;40(5):1173-9.

[24] Schiza SE, Simantirakis E, Bouloukaki I, Mermigkis C, Kallergis EM, Chrysostomakis S, et al. Sleep-disordered breathing in patients with acute coronary syndromes. J Clin Sleep Med 2012;8(1):21-6.

[25] Skinner MA, Choudhury MS, Homan SD, Cowan JO, Wilkins GT, Taylor DR. Accuracy of monitoring for sleep-related breathing disorders in the coronary care unit. Chest 2005;127(1):66-71.

[26] Van den Broecke S, Jobard O, Montalescot G, Bruyneel M, Ninane V, Arnulf I, et al. Very early screening for sleep-disordered breathing in acute coronary syndrome in patients without acute heart failure. Sleep Med 2014;15(12):1539-46.

[27] Collop NA, Anderson WM, Boehlecke B, Claman D, Goldberg R, Gottlieb DJ, et al. Clinical guidelines for the use of unattended portable monitors in the diagnosis of obstructive sleep apnea in adult patients. Portable Monitoring Task Force of the American Academy of Sleep Medicine. J Clin Sleep Med 2007;3(7):737-47.

[28] Kasai T, Bradley TD. Obstructive sleep apnea and heart failure: pathophysiologic and therapeutic implications. J Am Coll Cardiol 2011;57(2):119-27.

[29] Nakashima H, Katayama T, Takagi C, Amenomori K, Ishizaki M, Honda Y, et al. Obstructive sleep apnoea inhibits the recovery of left ventricular function in patients with acute myocardial infarction. Eur Heart J 2006;27(19):2317-22.

[30] Société de Pneumologie de Langue Française Société Française d'Anesthésie Réanimation Société Française de Cardiologie Société Française de Médecine du Travail Société Française d'ORL Société de Physiologie Société Française de Recherche et de Médecine du Sommeil. [Recommendations for clinical practice. Obstructive sleep apnea-hypopnea syndrome in adults]. Rev Mal Respir 2010;27(7):806-33.

[31] de Vries GE, van der Wal HH, Wijkstra P, van der Meer P. Response: a portable device as sleep-screening tool in the identification of obstructive sleep apnea in chronic heart failure: which value should we consider as cutoff? J Card Fail 2016;22(2):168.

[32] Freedman NS, Gazendam J, Levan L, Pack AI, Schwab RJ. Abnormal sleep/wake cycles and the effect of environmental noise on sleep disruption in the intensive care unit. Am J Respir Crit Care Med 2001;163(2):451-7.

[33] Javaheri S, Parker TJ, Liming JD, Corbett WS, Nishiyama H, Wexler L, et al. Sleep apnea in 81 ambulatory male patients with stable heart failure. Types and their prevalences, consequences, and presentations. Circulation 1998;97(21):2154-9.

[34] Yumino D, Wang H, Floras JS, Newton GE, Mak S, Ruttanaumpawan P, et al. Prevalence and physiological predictors of sleep apnea in patients with heart failure and systolic dysfunction. J Card Fail 2009;15(4):279-85. 